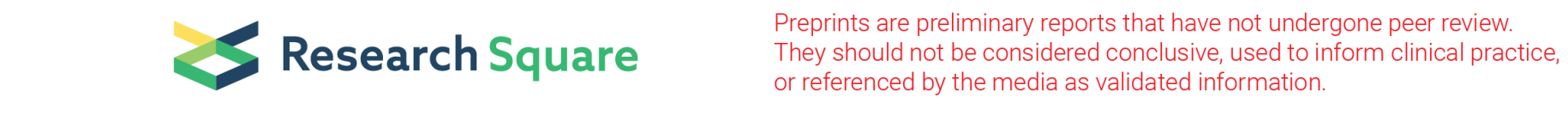

\title{
Individual Quality of Life and the Environment - Towards a Concept of Liveable Areas for Persons with Disabilities in Poland
}

\author{
Izabela Grabowska ( $\square$ igrabow@sgh.waw.pl ) \\ Warsaw School of Economics \\ Radosław Antczak \\ Warsaw School of Economics \\ Jan Zwierzchowski \\ Warsaw School of Economics \\ Tomasz Panek \\ Warsaw School of Economics
}

\section{Research Article}

Keywords: quality of life, disability, liveability, MIMIC, capability approach

Posted Date: December 21st, 2020

DOI: https://doi.org/10.21203/rs.3.rs-126451/v1

License: @ (i) This work is licensed under a Creative Commons Attribution 4.0 International License. Read Full License

Version of Record: A version of this preprint was published at BMC Public Health on April 17th, 2021. See the published version at https://doi.org/10.1186/s12889-021-10797-7. 


\section{Abstract}

\section{Background}

The United Nations Convention on the Rights of Persons with Disabilities highlights the need to create proper socio-economic and political conditions for persons with disabilities, with a special focus on their immediate living conditions. According to the Convention, these conditions should be built to ensure that persons with disabilities have the potential to enjoy a high quality of life (QoL), and this principle is reflected in the notion of liveable areas. The crucial aspect of this framework is the relationship between the individual QoL and the environment, broadly understood as the socio-economic as well as the technical conditions in which persons with disabilities function.

\section{Methods}

The basic research problem was to assess the relationship between individual QoL for the population with disabilities as a dependent variable and liveability indicators as independent variables, controlling for individual characteristics. The study used a dataset from the EU-SILC (European Union Statistics on Income and Living Conditions) survey carried out in 2015 in Poland. The research concept involved several steps. First, we created a variable measuring the QoL for the entire population with disabilities. To measure the multidimensional QOL, we used Sen's capability approach as a general concept, which was operationalised by the MIMIC (multiple indicators multiple causes) model. In the second step, we identified the liveability indicators available in the official statistics, and merged them with survey data. Finally, in the last step, we ran the regression analysis. We also checked the data for the nested structure.

\section{Results}

We confirmed that environmental conditions, defined as all conditions focused on creating liveable areas, played a significant role in shaping the QoL of persons with disabilities, and that this relationship held even after controlling for the demographic characteristics of the respondents. Moreover, we found that in addition to the general environmental conditions, the conditions created especially for persons with disabilities affected the QoL of these individuals.

\section{Conclusions}

The results illustrate the need to strengthen policies aimed at promoting the QoL of persons with disabilities by creating access to community assets and services that can contribute to improving the life chances of this population.

\section{Introduction}

The United Nations Convention on the Rights of Persons with Disabilities (UNCRPD) set several guidelines that have led to the adoption of a new approach to formulating public policy aimed at the population with disabilities. The new approach is based on the right of persons with disabilities to enjoy a high quality of life without discrimination or exclusion (Temple et al., 2018). The UNCRPD focuses on the macro-level systems that are expected to create proper socio-economic and political conditions for persons with disabilities, with a special focus on their immediate living conditions. These conditions should be built to ensure that persons with disabilities have the potential to enjoy a high quality of life (QoL). The notion of QoL reflects subjective and objective assessments of people's living conditions at the individual level. Hence, QoL can be seen as a link between the general values and rights embodied in the UNCRPD in particular, and the personal life of the individual (Brown, Schalock \& Brown, 2009; Buntinx \& Schalock, 2010; Verdugo et al., 2012). The crucial aspect of this framework is the relationship between the individual QoL and the environment, understood as the socio-economic as well as the technical conditions in which persons with disabilities function (UNDP, 20012). According to the UNCRPD, the interactions between persons with disabilities and the environment create a degree of inclusion and participation in all life spheres for this group.

Our aim in this article is to examine the relationship between the multidimensional quality of life of persons with disabilities and the level of liveability, as expressed by the environmental conditions at local level in Poland. The liveability concept is 
rarely used in disability research, even though environmental conditions (such as accessible space) are especially important for this group of people. The results of this research can make important contributions to the development of public policies aimed at improving the QoL of the population with disabilities, as reflected in the living conditions created in the local area. In the analysis, we took into account both the environmental conditions that were created the local level for the general population (with and without disabilities), and the conditions that were created specifically for the population with disabilities. For this reason, we treated the population with disabilities as a single group (although we are aware of the heterogeneity of this population) who need public support in certain dimensions of daily living in order to enjoy a good quality of life. Hence, in this analysis, we did not distinguish between people with particular types of disability or impairments, because from a public policy perspective, different groups within the disabled population tend to benefit from the application of the same public policy tools in certain dimensions, although the use of these tools may be tailored to address individual needs. As a model for measuring the quality of life of the population with disabilities, we applied the guidelines of the European Statistical System (Eurostat, 2011 and 2016), which was conceptually based on the capability approach formulated by Sen $(1985,1992)$. To operationalise this concept of measurement, we used the MIMIC model (multiple indicators multiple causes - Jöreskog, Goldberger, 1975). Up to now, this measurement concept has seldom been used for measuring the quality of life of persons with disabilities. This approach is consistent with the equality principles laid out in the UNCRPD.

In the study, we used data from the EU-SILC 2015 (The European Union Statistics on Income and Living Conditions) (Eurostat, 2020) carried out in Poland. To measure environmental conditions, we drew upon data from the Central Statistical Office in Poland at the LAU(local administrative units) level 1 (powiats), as well as from the Local Human Development Index calculated for powiats in Poland (UNDP, 2012).

The article has several sections. In the first section, we describe the knowledge gap we are seeking to fill, and our research design. In the subsequent sections, we elaborate our three main research steps: the conceptual part, the measurement part, and the analytical part; and we present our final results. We conclude with a discussion.

\section{Research design and data}

Our basic research design consists of an assessment of the relationship between the individual QoL of the population with disabilities as a dependent variable, and liveability indicators as independent variables, controlling for individual characteristics. Our theoretical considerations are based on two crucial concepts: QoL and liveability (conceptual framework). Based on the literature review, we establish the measurement model for the QoL of the entire population with disabilities. We then measure the liveability levels by identifying the liveability indicators and preparing them statistically for use in the regression model (measurement framework). Finally, in the last step, we run the regression model of QoL against liveability indicators, controlling for the socio-economic characteristics of the respondents (analytical framework).

The whole research design, which is composed of three steps (conceptual, measurement, and analytical parts), is presented in Figure 1.

In our research, we use three different data sources. Data on individual quality of life are drawn from the European Survey on Income and Living Conditions (EU-SILC), conducted in 2015 in Poland (Eurostat, 2020). This survey was carried out under an EU resolution on a representative sample of the Polish population aged 15 or older. The total sample size for 2015 was 27,997, and the sample size of persons with disabilities was 6,615 . This latter sample is used for further analysis. Of this population, $58.3 \%$ were women, $49.9 \%$ were aged 65 or older, $68.2 \%$ had less than secondary education, and $80.7 \%$ were not working. The liveability indicators at the local level are drawn from data collected for 2015 in the local database of the Central Statistical Office. The local development indicators at the local level come from the Local Human Development Index (LHDI) calculated for Poland for 2010 and 2007 (United Nations Development Programme, 2012).

\section{Background}

Conceptual framework 
The conceptual framework deals with two basic concepts within the context of disability. The first concept is the quality of life, with a special focus on the multidimensional character of and the measurement dilemmas associated with this indicator. The second concept refers to liveability and the creation of the living environment at the local level.

\section{- the concept of QoL}

Ideas about what constitutes "the good life" are rooted in ancient philosophy. Based on these foundations, three main constructs are used in the analysis of quality of life and well-being: hedonic well-being, eudaimonia, and life satisfaction. Hedonic well-being underlines the importance of emotions, affect, and subjectivity; eudaimonia points to the value of selfdevelopment and self-realisation; and life satisfaction refers to cognitive aspects of well-being (Sirgy, 2012).

Quality of life as a general concept has been studied in many fields, including economics, political science, psychology, philosophy, and medical science. The concept of QoL was introduced into the public discourse in the 1960s as an alternative to the prevailing focus on social development goals, which were at that time defined as improvements in material living conditions (Phillips 2006). Although the term is commonly used, there is no single, universally accepted definition of quality of life. The World Health Organization's definition focuses on individuals' perceptions of their position in life, and the extent to which it corresponds with their expectations. Other definitions include the satisfaction of needs, objective and subjective evaluations of different dimensions of life, agency, and the meaning of life. Interest in measuring QoL is increasing in the area of health care, where it is identified as an outcome of the efficacy of the treatment (Ferrans, 2005). Hence, as the concept of QoL is multifaceted, multidimensional, and ambiguous, a clear definition of it is needed before beginning research on quality of life (Stiglitz, et al. 2018). For the purposes of this article, we applied the individual-referenced definition outlined by Schalock, Keith, Verdugo, and Gomez (2010), in which they described QoL as a multidimensional phenomenon composed of core domains influenced by personal characteristics and environmental factors. The authors argued that these core domains are the same for all people, although their relative value and importance may vary individually.

Alongside these various definitions, different tools for measuring this phenomenon have been developed (e.g., Cummins, 2005; Felce, 1997; World Health Organization, 1997; Stiglitz et. al., 2018). Generally, there are two approaches to measuring QoL among persons with disabilities:

1. a measure constructed for the whole population and used to assess the QoL of different sub-groups, including persons with disabilities; and

2. a measure constructed and used specifically to assess the QoL of persons with particular limitations or disabilities.

The most complex measurement guidelines based on the first approach are provided by the final report of the Sponsorship Group on Measuring Progress, Well-being and Sustainable Development and the Task Force on the Multidimensional Measurement of Quality of Life (Eurostat, 2011 and 2016), which was accepted by the European Statistical System Committee. This proposal represents an extension of the QoL measurement concept of Berger-Schmitt and Noll (2000) operationalised in the framework of the European System of Social Indicators, which refers to recommendations of the Report on Measurement of Economic Performance and Social Progress (Stiglitz, Sen \& Fitoussi, 2009). Those reports stressed the multidimensional character of QoL, as well as the importance of combining both subjective and objective measures of QoL. Moreover, it was clearly stated that QoL should be assessed at both the individual and the community levels. In its final report, the Task Force on the Multidimensional Measurement of Quality of Life identified nine dimensions to be measured within the framework of the European Statistical System (Eurostat, 2016)... Each dimension comprises a set of indicators of a subjective and an objective character. This system of indicators enables the analysis of different life aspects within each dimension and their changes over time, as well as the relative assessment of QoL of individuals or households. However, it does not provide an explicitly formulated guide for operationalising the measurement, or a synthetic measure of QoL.

In the second approach, the concept of quality of life is used to assess the personal outcomes for persons with disabilities guaranteed under the UNCRPD (Karr, 2011). In this approach, quality of life is also considered as a multidimensional construct that includes physical, mental, and social dimensions (WHO, 1997), but it is used in the context of a particular disability or 
impairment. The influence of a particular type of disability or affliction on a person's quality of life is visible, and can be measured in different domains using both subjective and objective measures (i.e., Hornslien, Sandset, Bath, Wyller \& Berge, 2013; Taft, Magnusson, Ekstedt \& Malmgren, 2014).

These two approaches (general quality of life and QoL developed for persons with limitations) have important similarities. Both approaches assume that QoL should be composed of the same factors and relationships for all people; is experienced when a person's needs are met and when the individual has the opportunity to pursue life enrichment in major life activity settings; is comprised of both subjective and objective components; and is a multidimensional construct influenced by both individual and environmental factors (Karr, 2011; Verdugo et al., 2010). However, in the overall quality of life measurement approach, which measures QoL in the total population, the scope of the dimensions considered is relatively broad; whereas in the approach for measuring the QoL of persons with disability, the starting point is assessing functioning connected with various limitations.

An interesting proposal for measuring QoL that combines elements of both of the above-mentioned approaches is the capability approach, which was developed and refined by Sen $(1982,1985,1987,1999,2000,2010)$. This approach can be used to measure the QoL of the entire population, and specifically of the population with disabilities. The capability approach has been synthesised and practically applied by numerous authors in a wide variety of fields (Alkire, 2002; Robeyns, 2003, 2005; Kuklys, 2005; Comim, Qizilbash and Alkire, 2008; Schlosberg, 2012; Lorgelly et al, 2015; Slabbert, 2018). This concept is based on the assumption that commodities themselves are not crucial to achieving a high quality of life. Instead, Sen argued, it is the properties of these commodities that enable individuals to achieve their desired lifestyles. The term "capabilities" refers to a person's effective possibilities of realising achievements and fulfilling expectations; whereas the term "functionings" refers to a person's "beings and doings" that lead to these realised achievements and fulfilled expectations. To transform commodities into capabilities, three sets of conversion factors - personal, social, and environmental - are needed (Sen, 1992; Robeyns, 2005). Personal conversion factors (personal characteristics, such as metabolism, physical condition, intelligence, or gender) influence the types and degrees of capabilities a person can generate from commodities. Social conversion factors come from the society in which one lives (characteristics of social settings, social institutions, and power structures, such as social norms, public policies, societal hierarchies, rule of law, political rights, etc.). Environmental conversion factors emerge from the physical or built environment in which a person lives (environmental characteristics, such as climate, infrastructure, institutions, and public goods). The achieved functionings are the result of personal choices selected from the capabilities available, and are subject to personal preferences, social pressures, and other decision-making mechanisms. Moreover, they are constrained by personal, social, and environmental characteristics (Robeyns, 2005; Crocker, 2008). In the context of inequality analysis, people must have equal opportunities to function in their preferred way (Sen, 1982), as only then are they free to determine their capabilities - i.e., their potential, or possible ways of functioning - and to maximise their quality of life in accordance with these capabilities.

In this article, we have chosen to use the capability approach as a conceptual basis for the measurement model of the QoL. Moreover, we have constructed a measurement model for the whole population that we then apply to the population with disabilities. This macro-level approach could be used to create public policy guidelines aimed at the population with disabilities.

- Environment and QoL - towards a liveability concept

Living conditions, which should be shaped by public policy, especially at the local level, are associated with the concept of liveability. This concept originally comes from the literature on public management. The term "liveability" was used for the first time in the U.S. in 1970s in the context of discussions about urban sprawl and the problems caused by the degradation of the natural environment (Neighborhood Renewal Unit [NRU], 2005). Since then, the concept has mainly been developed in urban studies, although it originally also referred to rural areas (Howley, Scott \& Redmond, 2009; Zhang, 2012). While there are many definitions of liveability, the term is often used in connection with concepts such as quality of life, living environment, the quality of the place of residence, and sustainable living (Van Kamp, Leidemeijer, Marsman \& de Hollander, 2003). 
The term "liveability" was originally used to refer to residents' satisfaction with the area they are living in, and especially with the perception of living conditions in a particular area that should be shaped by both residents themselves and local authorities (Howley et al., 2009). This approach underlined two important elements of the liveability concept: (1) its relationship with the environment in which the local community functions; and (2) the importance of focusing on the short-term perspective.

Many authors have characterised the liveability concept as a set of elements that make life in a particular locale easier or more comfortable. Among these elements are economic opportunities, public security, medical services, mobility, and recreation (Clayden, McKoy \& Wild, 2007; Leby \& Hasim 2010; Van Kamp et al., 2003).

These elements come from the social, economic, and technical (psychical) sphere, and they create possibilities to realise individual QoL (Shafer, Koo Lee \& Turner, 2000). The interactions between the conditions created in the environment and the individual life situation determine the level of QoL (Newman, 1999; Pacione, 1990). In this context, spatial planning plays an important role, especially in cities (Smith, Nelischer \& Perkins, 1997).

Recently, the liveability concept has mainly been used in the context of meeting the social needs of residents (de Haan, Ferguson, Adamowicz, Johnstone, Brown \& Wong, 2013). Therefore, the aim of creating liveable areas is connected with social change, in particular through public policy, which should be initiated in those areas. This understanding of liveability is in line with that in the UNCRPD, which also takes as a starting point the rights and needs of one particular group - in this case, persons with disabilities - for whom public authorities should create the environmental conditions needed to enable them to realise their desired QoL. Having access to proper environmental conditions is seen as an essential component of the human rights of persons with disabilities.

An important issue raised in liveability studies is the measurement of this phenomenon. Two streams in measurement approaches can be distinguished. The first deals with satisfaction with the area where an individual lives, and its determinants (Howley et al., 2009; Parkes, Kearns \& Atkinson, 2002; Węziak-Białowolska, 2016). Howley et al. (2009) divided those determinants into two groups: (1) the first group of determinants are connected with liveability (access to employment, social, educational and cultural services, security, housing, etc.), (2) while the second group of determinants correspond to individual characteristics (age, sex, family status, etc.). Cheshmehzangi (2015) also identified similar factors, which he grouped into economic, social, cultural, and environmental categories. The second stream refers to more objective measures of liveability. There are many partial indicators created by researchers to measure the level of liveability of particular areas (performance indicators) (e.g., Balsas, 2004; Hogg, Medway \& Warnaby, 2001; Węziak-Białowolska, 2016).

\section{Methods}

\section{Measurement framework}

The measurement part refers to measurement models of QoL, liveability, as well as the definition of the population with disabilities.

\section{- disability}

The identification of persons with disabilities was based on limitations in activities of daily living (ADL), a commonly used measure of disability. This question has three categories: 1) strongly limited in daily activities; 2) limited, but not strongly; and 3) not limited at all. All persons who were limited in their activities to some extent ( 1 and 2 ) were defined as those with disabilities.

\section{- quality of life}

To establish a measure of multidimensional QoL, we used the guidelines of the European Statistical System (Eurostat, 2011 and 2016) due to its multidimensionality and potential for operationalisation. All information on the access to the EU-SILC dataset can be found on the URL (https://ec.europa.eu/eurostat/web/microdata/european-union-statistics-on-income-and- 
living-conditions) - access on May 2020. To conceptualise the measurement approach, we used Sen's capability approach $(1985,1992)$.

Our QoL measurement model was based on the MIMIC model, which was formulated by Hauser and Goldberger (1971), and was popularised by Jöreskog and Goldberger (1975). The operationalisation of QoL in the MIMIC model, according to Krishnakumar (2007), was performed as follows. Capabilities are endogenous latent variables, which can be estimated on the basis of chosen achieved functionings, and are represented by observable exogenous variables (observable symptoms of QoL). The combined analysis of capabilities sets and achieved functionings enables the multidimensional measurement of QoL. Conversion factors (individual, social, and environmental), which are represented by exogenous variables, determine an individual's capabilities.

The starting point for establishing the MIMIC model to measure QoL was to assign capabilities to the dimensions of quality of life presented in the European Statistical System (Eurostat, 2011, 2016). The model includes nine dimensions: material living conditions, productive or main activity, health, education, leisure and social interactions, economic and physical safety, governance and basic rights, natural and living environment, and overall experience of life. Each of these dimensions is represented by a set of determinants (including individual characteristics of the respondents, such as gender, age, place of residence, or health status) and a set of symptoms, which are drawn from a directly observable list of variables in the EU-SILC questionnaires. The list of symptoms for each domain is included in Annex 1.

Each life domain is represented by an unobservable latent variable, which can be estimated based on two sets of observable variables. First, in the reflective part of the model (symptoms), these variables can be interpreted as realised functionings. The formative part of the model (structural sub-model) is constructed based on the individuals' personal, social, and environmental exogenous characteristics, which are the conversion factors that strengthen or weaken their capabilities, and influence the process of the transformation of available resources into achieved functioning.

To estimate the overall life quality indicator for each person, we used a formative approach (Diamantopoulos \& Siguaw, 2006; Edwards \& Bagozzi, 2000; Pearl, 2014). The formative indicators included in this approach are considered as determinants of a multidimensional latent variable. In our study, the overall quality of life is described as a latent variable influenced by the dimension (group) quality of life indicators. In this case, the measurement model is based on a principal component method, which is often used for formative indicators (Maggino \& Zumbo, 2012). In this method, it is assumed that the overall quality of life indicator is a linear combination of the dimension (group) life quality indicators, and that there is no measurement error (Panek, 2016). Finally, the quality of life scores were standardised. The analytical framework is presented in Figure 2 . The results of the MIMIC model estimations (for the entire population - with and without disabilities) are presented in the Annex 2.

\section{- liveability}

To operationalise the liveability level, we have chosen to measure it using a set of appropriate indicators. Liveability, as elaborated at the conceptual level of the paper, refers to the living conditions in the local area. This also implies that the measurement should be made at the local level. In the Polish context, we decided to use the LAU level 1 (powiaty). As well as reflecting the local character, an advantage of using the LAU level 1 is that more data (indicators) are available at this level than at the LAU level 2 (gminy). This is especially the case for indicators of public policy aimed at the population with disabilities. Certain indicators that reflect the liveability level of a local area in the context of the situation of the population with disabilities can be grouped into two categories:

- those affecting the whole population (with and without disabilities). It should, however, be noted that the same environmental settings may affect the quality of life of the population with disabilities differently than the population without disabilities.

- those that are specifically related to various disabilities (Visagie, Eide, Dyrstad, Mannan, Swartz, Schneider \& MacLachlan, 2017).

We decided to use simultaneously two groups of indicators based on the above classification. 
The first indicator refers to the general environmental conditions created at LAU level 1 for the total population. For this purpose, we used the Local Human Development Index, LHDI (UNDP, 2012). The LHDI refers to the general living conditions in the powiat, and is a very complex measure, although it does not distinguish between the conditions created for the population with and without disabilities. The LHDI consists of three dimensions (health, education, and wealth), and is reflected by several indicators: life expectancy at birth, crude death rates, the fraction of children aged 3-4 taking part in pre-school education, the average results of mathematics and science final exams at the lower-secondary educational level, and the average level of wealth of the inhabitants (UNDP, 2012). The higher the value of the indicator, the higher the general liveability level. The LHDI for Poland was calculated for 2007, 2008, 2009, and 2010. In the further analysis, we decided to use the LHDI measured for 2010 as a general approximation of the environmental conditions created for the entire population. There is a time lag between the basic dataset used to establish individual QoL (a dependent variable used in the regression model described above) (EUSILC 2015) and the LHDI (2010). However, in the past, this measure has been quite stable over time for Poland.

The second group of indicators refers to the environmental conditions established with a focus on persons with disabilities. In the first step, we searched for proper partial indicators that reflect, at least to some extent, public policies aimed at the population with disabilities at the LAU level 1. We found that while each of proposed partial indicators alone do not provide enough information on the specific conditions for persons with disabilities in the powiats, the proposed group of indicators provide an approximation of such information. The proposed indicators refer to the liveability concept in the economic and social spheres. Indicators that refer to the technical sphere, defined as the accessibility of public spaces for persons with different disabilities, are not included in the list of indicators below due to a lack of such data at the LAU level 1 for Poland. The set of partial indicators is as follows:

- Employment activity: the number of unemployed persons with disabilities in relation to the number of persons with disabilities in the powiats. This indicator reflects not only the economic activity of the population with disabilities, but also the accessibility of public employment services.

- Social assistance: the number of families receiving support from social assistance due to disability in relation to the number of persons with disabilities in the powiats. This indicator captures not just cash benefits, but also (as is crucial here) social services such as care services (basic and specialised). For this reason, we treat this indicator as a reflection of the accessibility of basic social services.

- Access to health care: this is measured by the number of general practitioners in relation to the number of persons with disabilities in the powiats. This indicator reflects the general accessibility of basic health services at the powiat level.

- Primary education: this is measured as the number of special units in primary schools and gymnasiums for children and youth with special learning needs. This indicator reflects the accessibility of proper educational services (at the basic level) relatively close to the place of residence.

The above-mentioned indicators come from an online database of the Polish Central Statistical Office. The data are from 2015, as this is the period used for the QoL measurement. This information refers to 2011 , and is drawn from the last national census. We assume that these variables express the attitudes of local authorities towards creating conditions favourable for persons with disabilities in the powiats. The above-mentioned indicators are correlated. Therefore, in order to introduce the full information contained in these indicators into the regression model, we applied the principle component method. The new variables established in that method fulfil the following criteria: (1) they are not corelated (orthogonal); (2) they are normalised (the sum of squares of linear combination coefficients are equal to one); and (3) they appropriately approximate the real variables. We decided to use in the regression model the principle components, which have meaningful interpretations. To do so, we had to rotate the results of the principle component analysis. Finally, we have accepted the model with two components (factors). The first factor is comprised of access to health care and primary education, and is related to the services available for persons with disabilities. The second factor is related to living conditions, and includes two variables: employment activity and social assistance. Those two principal components account for $74.9 \%$ of the total variance of the data. Both factors are then used for regression models to assess the influence of environmental factors on overall quality of life. 
Indicators from both groups are used in the regression analysis of the multidimensional quality of life against the liveability indicators. The indicators reflecting the environmental conditions for persons with disabilities (living conditions and services factors - second group indicators) are orthogonal, but the living conditions variable is highly correlated ( $r=0.69)$ with the LHDI (first group indicator). Hence, we have prepared two separate regression models: one for the LHDI, and another for the environmental conditions for persons with disabilities.

\section{Analytical framework -regression model}

Our basic research design refers to the regression model with the multidimensional QoL score as a dependent variable and indicators that express the liveability level as an independent variable, controlling for the socio-economic characteristics of individuals.

The most commonly used method for modelling geographical data is multilevel modeling. Therefore, in the first step of the analysis, we checked the assumptions for this approach. First, we assessed the nested structure of the data, whereby level 1 consists of individuals and level 2 consists of LAU level 1 (powiats). Next, we ran empty models for the two-level structure. We then calculated the ICC (interclass correlation coefficient), which turned out to be very low (ICC=0.004), suggesting that a twolevel structure is unnecessary. Moreover, we checked the design effect (deff $=1$ ), which also suggests that the data on QoL are not hierarchical at the LAU level 1. As our initial assessment pointed to the inappropriateness of multilevel structure of the data, we decided to apply one- instead of two-level models to answer the research questions. As the dependent variable - i.e., the individual quality of life score - is a continuous variable, we applied an OLS regression with a step-wise procedure. Control variables were gradually introduced into the model.

\section{Results}

\section{Characteristics of the population with disabilities in Poland}

The first step in our analysis was to briefly describe the characteristics of the population with disabilities in Poland based on the data from the EU-SILC survey, as well as to perform a descriptive analysis of the dependent variable (quality of life scores) and the independent variables (liveability indicators assigned to each respondent according to their place of residence). The descriptive statistics of those variables are provided in the Table 1.

The highest quality of life scores were noted for men, and for people who were below age 45, living in four-person households, married, and from the biggest cities. These groups were found to enjoy the highest quality of life. The most excluded groups (with the lowest QoL) were identified as women, the oldest age groups, single and divorced individuals, and people living in rural areas.

The total average value for the LHDI (first group indicator) was 46.13. Women were found to have above-average scores, regardless of their age and marital status. We also observed a clear household size and place of residence gradient. The LHDI score decreased with household size, and rose as the size of the place of residence increased. Residents of big cities clearly had the highest LHDI scores.

The values for both environmental variables that reflect the liveability levels of persons with disabilities (second group indicators) were standardised. The values for services were highest for the oldest age group, singles, and people living in big cities. The maximum scores for living conditions were observed for people who were aged 65-74, living in five-person households, divorced, and inhabitants of mid-sized towns.

\section{Table 1. Descriptive characteristic of independent variables}




\begin{tabular}{|c|c|c|c|c|c|c|c|c|c|c|}
\hline & \multicolumn{2}{|c|}{$\begin{array}{l}\text { Overall Quality of } \\
\text { Life }\end{array}$} & \multicolumn{2}{|c|}{ LHDI_2010 } & \multicolumn{2}{|c|}{$\begin{array}{l}\text { Environment - } \\
\text { services }\end{array}$} & \multicolumn{2}{|c|}{$\begin{array}{l}\text { Environment - living } \\
\text { conditions }\end{array}$} & \multicolumn{2}{|c|}{ Sample } \\
\hline & Mean & Std Dev. & Mean & $\begin{array}{l}\text { Std } \\
\text { Dev. }\end{array}$ & Mean & Std Dev. & Mean & Std Dev. & $\mathrm{n}$ & $\%$ \\
\hline Total & 0.00 & 1.00 & 46.13 & 15.39 & 0.00 & 1.00 & 0.00 & 1.00 & 6615 & 100.0 \\
\hline \multicolumn{11}{|l|}{ Sex } \\
\hline Man & 0.08 & 1.02 & 45.94 & 15.69 & 0.01 & 1.04 & -0.02 & 0.99 & 2756 & 41.7 \\
\hline Woman & -0.06 & 0.98 & 46.27 & 15.16 & -0.01 & 0.97 & 0.02 & 1.01 & 3859 & 58.3 \\
\hline \multicolumn{11}{|l|}{ Age } \\
\hline below 45 & 0.27 & 1.12 & 46.78 & 14.92 & 0.02 & 0.94 & -0.03 & 1.00 & 849 & 12.8 \\
\hline $45-54$ & 0.01 & 1.01 & 43,59 & 13.46 & -0.16 & 0.79 & -0.02 & 0.97 & 757 & 11.4 \\
\hline $55-64$ & -0.07 & 0.98 & 46.17 & 15.58 & -0.03 & 1.00 & 0.01 & 0.99 & 1707 & 25.8 \\
\hline $65-74$ & 0.01 & 0.98 & 45.97 & 15.42 & 0.01 & 1.00 & 0.05 & 1.02 & 1581 & 23.9 \\
\hline $75+$ & -0.12 & 0.92 & 47.01 & 16.21 & 0.09 & 1.12 & -0.03 & 1.01 & 1721 & 26.0 \\
\hline \multicolumn{11}{|l|}{ Household size } \\
\hline single & -0.28 & 0.99 & 48.71 & 17.00 & 0.21 & 1.18 & -0.06 & 0.98 & 1169 & 17.7 \\
\hline 2 persons & 0.07 & 1.00 & 47.50 & 15.66 & 0.07 & 1.02 & 0.04 & 1.02 & 2572 & 39.0 \\
\hline 3 persons & 0.05 & 1.01 & 45.76 & 14.38 & -0.06 & 0.94 & -0.06 & 0.98 & 1138 & 17.3 \\
\hline 4 persons & 0.17 & 0.98 & 45.99 & 15.61 & 0.01 & 1.03 & 0.02 & 1.03 & 807 & 12.2 \\
\hline $\begin{array}{l}5 \text { or more } \\
\text { persons }\end{array}$ & 0.09 & 0.94 & 40.10 & 10.97 & -0.37 & 0.45 & 0.05 & 0.99 & 906 & 13.7 \\
\hline \multicolumn{11}{|l|}{ Marital status } \\
\hline single & -0.14 & 1.09 & 46.73 & 16.19 & 0.04 & 1.03 & -0.06 & 0.95 & 1067 & 16.2 \\
\hline married & 0.19 & 0.94 & 45.40 & 14.73 & -0.06 & 0.93 & 0.02 & 1.01 & 3919 & 59.5 \\
\hline divorced & -0.34 & 1.11 & 50.56 & 16.65 & 0.27 & 1.14 & 0.08 & 1.09 & 421 & 6.4 \\
\hline widowed & -0.26 & 0.96 & 46.31 & 15.85 & 0.04 & 1.08 & -0.04 & 0.98 & 1606 & 24.4 \\
\hline \multicolumn{11}{|c|}{ Place of residence } \\
\hline cities $500 \mathrm{k}+$ & 0.23 & 1.00 & 72.65 & 16.04 & 1.85 & 1.38 & -0.52 & 0.63 & 681 & 10.3 \\
\hline $\begin{array}{l}\text { cities 100k- } \\
499 \mathrm{k}\end{array}$ & 0.10 & 1.02 & 57.03 & 7.95 & 0.65 & 0.94 & 0.03 & 1.02 & 1160 & 17.6 \\
\hline towns $20 k-99 k$ & -0.04 & 0.99 & 45.70 & 9.88 & -0.30 & 0.36 & 0.14 & 1.09 & 1239 & 18.8 \\
\hline $\begin{array}{l}\text { towns less than } \\
20 \mathrm{k}\end{array}$ & 0.02 & 1.05 & 38.16 & 8.29 & -0.42 & 0.37 & 0.05 & 0.91 & 954 & 14.5 \\
\hline rural & -0.11 & 0.96 & 37.29 & 9.84 & -0.49 & 0.33 & 0.04 & 1.02 & 2556 & 38.8 \\
\hline
\end{tabular}

Source: own calculations ( $n=6592)$. 
Two separate models for the two liveability indicators were taken into account in our research: the LHDI, as an approximation of general living conditions (first group indicator), and two variables that reflect the environmental conditions for people with disabilities (second group indicator). The control variables reflect the typical characteristics of individuals: sex, age, household size, marital status, and type of place of residence. We excluded variables such as education or income because they were used to create the dependent variable (QoL). We developed four models for each of the independent variables, separately for the LHDI and for the environmental conditions for people with disabilities, and introduced the control variables sequentially. Thus, in Tables 2 and 3, we present the results of eight models.

Table 2. The relationship between local HDI and individual quality of life - results of OLS regression

\begin{tabular}{|c|c|c|c|c|c|c|c|c|c|c|c|c|}
\hline \multirow[b]{2}{*}{ Variable } & \multicolumn{3}{|c|}{ Model 1} & \multicolumn{3}{|c|}{ Model 2} & \multicolumn{3}{|c|}{ Model 3} & \multicolumn{3}{|c|}{ Model 4} \\
\hline & Coef. & & $\begin{array}{l}\text { Std. } \\
\text { Err. }\end{array}$ & Coef. & & $\begin{array}{l}\text { Std. } \\
\text { Err. }\end{array}$ & Coef. & & $\begin{array}{l}\text { Std. } \\
\text { Err. }\end{array}$ & Coef. & & $\begin{array}{l}\text { Std. } \\
\text { Err. }\end{array}$ \\
\hline Ihdi_2010 & 0,009 & $\star \star \star$ & 0,001 & 0,009 & $\star \star \star \star ~$ & 0,001 & 0,009 & 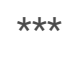 & 0,001 & 0,007 & $\star \star \star ~$ & 0,001 \\
\hline \multicolumn{13}{|l|}{$\begin{array}{l}\text { Sex (ref. } \\
\text { man) }\end{array}$} \\
\hline woman & $-0,012$ & $\star \star \star$ & 0,023 & $-0,084$ & $\star \star \star \star ~$ & 0,023 & $-0,039$ & & 0,024 & $-0,041$ & * & 0,024 \\
\hline \multicolumn{13}{|c|}{ Age (ref. below 45) } \\
\hline $45-54$ & $-0,007$ & & 0,046 & $-0,065$ & & 0,046 & $-0,231$ & *** & 0,047 & $-0,225$ & 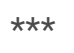 & 0,047 \\
\hline $55-64$ & $-0,016$ & $\star \star \star$ & 0,038 & $-0,145$ & $\star \star \star ~$ & 0,040 & $-0,341$ & *** & 0,043 & $-0,333$ & $\star \star \star$ & 0,043 \\
\hline $65-74$ & $-0,009$ & ** & 0,039 & $-0,055$ & & 0,041 & $-0,257$ & 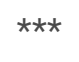 & 0,045 & $-0,252$ & 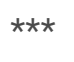 & 0,045 \\
\hline $75+$ & $-0,024$ & $\star \star \star$ & 0,039 & $-0,167$ & *** & 0,041 & $-0,307$ & 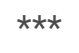 & 0,047 & $-0,299$ & 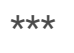 & 0,047 \\
\hline \multicolumn{13}{|l|}{$\begin{array}{l}\text { Household } \\
\text { size (ref. } 1 \\
\text { person) }\end{array}$} \\
\hline 2 persons & & & & 0,298 & $\star \star \star ~$ & 0,033 & 0,000 & & 0,038 & 0,006 & & 0,038 \\
\hline 3 persons & & & & 0,240 & 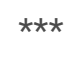 & 0,040 & $-0,023$ & & 0,043 & $-0,007$ & & 0,043 \\
\hline 4 persons & & & & 0,285 & 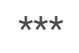 & 0,044 & $-0,010$ & & 0,047 & 0,012 & & 0,047 \\
\hline 5 and more & ersons & & & 0,283 & 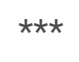 & 0,042 & 0,003 & & 0,045 & 0,043 & & 0,046 \\
\hline \multicolumn{13}{|c|}{$\begin{array}{l}\text { Marital status (ref. } \\
\text { married) }\end{array}$} \\
\hline single & & & & & & & $-0,542$ & 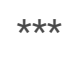 & 0,042 & $-0,537$ & 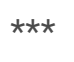 & 0,042 \\
\hline divorced & & & & & & & $-0,522$ & 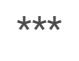 & 0,052 & $-0,532$ & *** & 0,052 \\
\hline widowed & & & & & & & $-0,376$ & 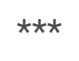 & 0,035 & $-0,370$ & 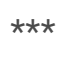 & 0,035 \\
\hline \multicolumn{13}{|c|}{$\begin{array}{l}\text { Place of residence } \\
\text { (ref, } 500 \mathrm{k}+)\end{array}$} \\
\hline $100 k-499 k$ & & & & & & & & & & $-0,012$ & & 0,056 \\
\hline $20 k-99 k$ & & & & & & & & & & $-0,017$ & & 0,060 \\
\hline $\begin{array}{l}\text { less than } \\
20 \mathrm{k}\end{array}$ & & & & & & & & & & 0,000 & & 0,065 \\
\hline rural & & & & & & & & & & $-0,132$ & ** & 0,062 \\
\hline _cons & $-0,023$ & & 0,049 & $-0,536$ & & 0,062 & 0,024 & & 0,070 & 0,150 & & 0,108 \\
\hline
\end{tabular}


Source: own calculations.

Table 3. The relationship between environmental factors and individual quality of life - results of OLS regression

\begin{tabular}{|c|c|c|c|c|c|c|c|c|c|c|c|c|}
\hline & M1 & & & M2 & & & M3 & & & M4 & & \\
\hline Variable & Coef. & & $\begin{array}{l}\text { Std } \\
\text { Err. }\end{array}$ & Coef. & & $\begin{array}{l}\text { Std } \\
\text { Err. }\end{array}$ & Coef. & & $\begin{array}{l}\text { Std } \\
\text { Err. }\end{array}$ & Coef. & & $\begin{array}{l}\text { Std } \\
\text { Err. }\end{array}$ \\
\hline Services & 0,088 & $\star \star \star \star$ & 0,016 & 0,097 & $\star \star \star$ & 0,017 & 0,097 & $\star \star \star$ & 0,016 & 0,030 & & 0,024 \\
\hline $\begin{array}{l}\text { Living } \\
\text { Conditions }\end{array}$ & $-0,040$ & 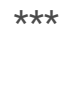 & 0,013 & $-0,043$ & $\star \star \star \star ~$ & 0,013 & $-0,045$ & $\star \star \star$ & 0,013 & $-0,036$ & $\star \star \star$ & 0,013 \\
\hline \multicolumn{13}{|l|}{$\begin{array}{l}\text { Sex (ref. } \\
\text { man) }\end{array}$} \\
\hline woman & $-0,162$ & $\star \star \star \star ~$ & 0,028 & $-0,118$ & $\star \star \star \star ~$ & 0,028 & $-0,072$ & $\star \star$ & 0,028 & $-0,079$ & $\star \star \star$ & 0,028 \\
\hline \multicolumn{13}{|c|}{ Age (ref. below 45) } \\
\hline $45-54$ & $-0,196$ & $\star \star \star$ & 0,056 & $-0,185$ & $\star \star \star$ & 0,056 & $-0,294$ & $\star \star \star$ & 0,057 & $-0,282$ & $\star \star \star ~$ & 0,057 \\
\hline $55-64$ & $-0,276$ & $\star \star \star$ & 0,047 & $-0,255$ & $\star \star \star$ & 0,049 & $-0,385$ & $\star \star \star *$ & 0,052 & $-0,367$ & $\star \star \star$ & 0,052 \\
\hline $65-74$ & $-0,202$ & $\star \star \star$ & 0,048 & $-0,153$ & $\star \star \star$ & 0,051 & $-0,289$ & $\star \star \star$ & 0,054 & $-0,275$ & $\star \star \star$ & 0,054 \\
\hline $75+$ & $-0,324$ & $\star \star \star$ & 0,048 & $-0,224$ & $\star \star \star$ & 0,052 & $-0,325$ & $\star \star \star$ & 0,057 & $-0,313$ & 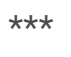 & 0,057 \\
\hline \multicolumn{13}{|c|}{ Household size (ref. 1 person) } \\
\hline 2 persons & & & & 0,346 & 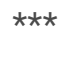 & 0,036 & 0,034 & & 0,044 & 0,042 & & 0,044 \\
\hline 3 persons & & & & 0,299 & 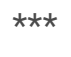 & 0,047 & 0,002 & & 0,052 & 0,027 & & 0,052 \\
\hline 4 persons & & & & 0,321 & $\star \star \star$ & 0,052 & 0,009 & & 0,057 & 0,048 & & 0,057 \\
\hline 5 and more & ersons & & & 0,288 & $\star \star \star$ & 0,051 & $-0,012$ & & 0,056 & 0,058 & & 0,056 \\
\hline \multicolumn{13}{|c|}{ Marital status (ref. married) } \\
\hline single & & & & & & & $-0,495$ & $\star \star \star$ & 0,053 & $-0,489$ & 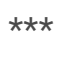 & 0,052 \\
\hline divorced & & & & & & & $-0,542$ & 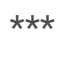 & 0,061 & $-0,562$ & 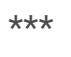 & 0,060 \\
\hline widowed & & & & & & & $-0,390$ & $\star \star \star$ & 0,042 & $-0,378$ & $\star \star \star ~$ & 0,042 \\
\hline \multicolumn{13}{|c|}{ Place of residence (ref, $500 \mathrm{k}+$ ) } \\
\hline $100 k-499 k$ & & & & & & & & & & $-0,028$ & & 0,068 \\
\hline $20 k-99 k$ & & & & & & & & & & $-0,085$ & & 0,078 \\
\hline $\begin{array}{l}\text { less than } \\
20 \mathrm{k}\end{array}$ & & & & & & & & & & $-0,120$ & & 0,081 \\
\hline rural & & & & & & & & & & $-0,272$ & $\star \star \star$ & 0,077 \\
\hline _cons & 0,324 & & 0,043 & 0,000 & & 0,058 & 0,494 & & 0,069 & 0,614 & & 0,095 \\
\hline
\end{tabular}

Source: own calculations.

The results confirm that environmental conditions play a significant role in shaping individual quality of life for persons with disabilities. Local HDI was found to have a positive influence on individual quality of life, which means that the higher the level of development of the local area (powiat), the higher the quality of life of individuals with disabilities living in this area. This relationship was shown to hold even after controlling for demographic characteristics of respondents. 
Both variables that refer to the environmental conditions for persons with disabilities - services and living conditions - were also found to be significant for quality of life. While this significance held after controlling for the demographic characteristics of individuals, services were no longer significant after the introduction of the place of residence variable into the model. This means that the availability of services was highly related to the size of the place of residence. Living in a rural area had a negative influence on individual quality of life, as it was associated with limited access to services (education, healthcare) for persons with disabilities.

Due to the nature of the environmental variables, the direction of the influence was different: i.e., it was positive for services and negative for living conditions. This means that the better the access to services, the higher the quality of life was for persons with disabilities; and the greater the level of deprivation in the area (higher unemployment, higher share of persons receiving social benefits), the lower the individual quality of life.

It is also to worth noting that the influence of access to services was stronger than the level of deprivation (for models without the size of the place of residence). The effects of the environmental factors (services and living conditions) were also much stronger than those of the LHDI.

Our results are in line with those of other studies on the environmental barriers that the population with disabilities typically encounter. Many studies have shown that individuals with disabilities face more severe environmental barriers than individuals without disabilities (Neille \& Penn, 2015; O'Donovan, Doyle \& Gallagher, 2009; Visagie et al., 2017). There are also studies on the relationship between environmental conditions at local level and health or daily functioning for the vulnerable population of older persons, who tend to experience limitations of daily living similar to those of the population with disabilities (Guo, Hon Chan, Chang, Liu \& Yip, 2019; Milton, Mold, Tinker \& Herrick, 2019; Rachele, Sugiyama, Davies, Loh, Turrell, Carver \& Cerin, 2019; Yafei, Dijst, Faber, Geertman \& Cui, 2017). The findings of these studies highlight the important role the environment plays in different life domains.

\section{Conclusions}

\section{Discussion and public policy implications}

Our original contribution in this research is of both a methodological and a cognitive nature. First, based on the literature review in the conceptual part, we established a multidimensional model for measuring QoL, which can be applied not only to the population with disabilities (as we did in this paper), but also more broadly to other population groups, thereby enabling comparisons between groups. Second, we linked the concept of liveability with the disability context. Moreover, we provided a measurement concept of liveability, both for general living conditions and for conditions created with a specific focus on persons with disabilities. Finally, we used an analytical approach to measure the relationship between the individual quality of life of the population with disabilities and the external (environmental) conditions expressed by liveability indicators at the LAU level 1 in Poland. This research design allowed us to quantify the meaning of external factors for the multidimensional quality of life of the population with disabilities. We demonstrated that environmental conditions played an important role in shaping the individual quality of life of persons with disabilities. Moreover, we found that the environmental conditions that had an impact on the QoL of this group were not just general conditions, but the conditions created especially for persons with disabilities. This illustrates the need to strengthen the policies aimed at persons with disabilities.

Moreover, we introduced the local level as a crucial issue in the creation of a disability-friendly environment. Existing studies have shown that the external environment and its resources have a significant impact on the functioning of persons with disabilities, but usually at the country level (Reinhardt, Miller, Stucki, Sykes \& Gray, 2011). In our approach, we focused on the concept of liveable local areas, which should create capabilities for persons with disabilities to achieve a higher QoL. Such an approach is in line with the UNCRPD, which highlighted the importance of the local environmental conditions in protecting the rights of persons with disabilities. 
The results of our research have some implications for the policy agenda aimed at persons with disabilities in Poland. First, it have provided crucial information that can be used in developing evidence-based policies targeted to the population with disabilities at the local level (Pawson, 2006). Special attention should be paid to the opportunities created in the local environment, while taking into account the different needs of persons with disabilities. Our results emphasise the necessity to create public policies aimed at persons with disabilities at the local level. This idea is quite obvious. For more details on the policy recommendations stemming from our analysis, we refer to the work of Toro-Hernandez et al. (2020), in which the authors analysed the factors that limit access to community assets for the population with disabilities. Taking this approach, we can see the connection between policies designed to facilitate general improvements in living conditions, and measures targeted at persons with disabilities. The policies aimed at persons with disabilities should be seek to improve their access to community assets, which are created for the entire population. Thus, public policies at the local level should be aimed not only at creating additional services or assets for the population with disabilities, but at making the existing ones available to the population with disabilities. Such policy measures should take into account the limitations faced by the population with disabilities at the personal level (e.g., lack of financial resources, inaccessible housing), interpersonal level (e.g., lack of personal assistance or aid), and community level (e.g., lack of accessible public transportation and inaccessible buildings) (Emerso \& Einfeld,2011; Toro-Hernandez et al., 2020). The failure to implement measures that enable persons with disabilities to use community assets and to take advantage of other opportunities to enhance their life chances can be seen as discriminatory or exclusionary towards this population (Temple et al., 2018).

Measures or regulations created at the state level seem to be insufficient, as in many cases the above-mentioned limitations are made worse by system-level barriers (e.g., a lack of effective enforcement of the legal framework). Thus, having a good understanding of the limitations of the living conditions of persons with disabilities is crucial. Such limitations should be identified at the local level in particular, as it is only by using this approach that measures can be tailored to the specific needs of the local population. One method that could be used to develop such measures is the service design process, which enables policymakers to look at solutions through the eyes of persons with different types of disabilities (e.g., Beck et al., 2014). In practice, using this approach demands more personalisation of support schemes for persons with disabilities, given that the extent to which persons with disabilities can achieve a good quality of life is influenced by the nature of their impairments; their individual, family, and community characteristics; as well as the environmental conditions created at local levels (Malbon et al., 2019).

The conditions that enable persons with disabilities to enjoy a higher quality of life through the creation of high-quality living spaces are mostly shaped by local authorities. Hence, the institutional efficiency of local authorities, and their ability to listen to and cooperate with other crucial actors, are also essential elements in this context. Local policy should be shaped in constant dialogue with persons with disabilities and their representatives, care providers, service providers, and other institutions supporting persons with disabilities, especially non-governmental organisations (Grills et al., 2020). The cooperation of these stakeholders can increase access to different assets and services for persons with disabilities, which can, in turn, increase their quality of life.

Local conditions and living space influence the overall multidimensional quality of life through their impacts on particular dimensions of quality of life. These impacts can be associated with access to high-quality services, especially social services. This is clearly visible in such dimensions as health or education (Field \& Jette, 2007). Our research results confirm these findings, and draw attention to social services as a crucial determinant of the multidimensional quality of life for persons with disabilities.

Our research also highlights that material conditions, and opportunities to improve those conditions in the local areas where persons with disabilities live, are important determinants of multidimensional QoL. The main reasons why the population with disabilities tend to have poor material conditions it that their economic activities are limited and they need more medical treatment and rehabilitation than the general population. Allmark and Machaczek (2015) reported similar results, and suggested that improving the financial capabilities of persons with disabilities would directly improve their QoL, and would indirectly improve their health. Although social benefits and allowances are regulated in Poland by state law, there are many

Page $14 / 22$ 
possibilities at the local level to improve the financial situation of persons with disabilities, such as through the creation of job opportunities at social enterprises (European Commission, 2020).

The basic limitation of our study is the scarcity of the data on liveability and environmental conditions at the local level, especially in the context of disability. Thus, there is a need for a proper system that monitors these conditions, and fully monitors compliance with the UNCRPD. Having a broader set of liveability indicators would diversify and enrich the analysis. Another potential subject for future qualitative and quantitative analysis is the expiration of the liveability concept for persons with disabilities. A big opportunity for future research is to further develop the model for measuring QoL so that it can perform complex analyses of overall QoL, as well as of QoL in particular domains. The model can also be used for cross-country and cross-group comparisons.

\section{Abbreviations}

Deff - design effect

EU-SILC - European Union Statistics on Income and Living Conditions

ICC - interclass correlation coefficient LAU - local administrative units

LHDI - Local Human Development Index

QoL - quality of life

MIMIC - multiple indicators multiple causes

UNCRPD - The United Nations Convention on the Rights of Persons with Disabilities

\section{Declarations}

\section{Ethics approval and consent to participate}

Nor applicable

\section{Consent for publication}

Not applicable

\section{Availability of data and materials}

The datasets used and/or analysed during the current study are available from the corresponding author on reasonable request.

\section{Competing interests}

The authors declare that they have no competing interests

\section{Funding}

The research was conducted at Warsaw School of Economics - BS2020.

\section{Authors' contributions}

IG coordinated the work of other authors and prepared literature review on QoL, described data results and prepared conclusions, RA made regression analysis of the environmental factors on the quality of life and contributed to literature review on quality of life and the description of results. JZ made calculations of the MIMIC model. TP prepared the 
methodological framework for the measurement of the quality of life using capability approach and MIMIC model as its operationalization. All authors read and approved the final manuscript.

\section{Acknowledgements}

Not applicable

\section{References}

Alkire S. Valuing Freedom: Sen’s Capability Approach and Poverty Reduction. Oxford: Oxford University Press; 2002.

Allmark P, Machaczek K. Financial capability, health and disability. BMC Public Health. 2015; 15:243. doi: 10.1186/s12889-0151589-5.

Balsas C. Measuring the liveability of an urban space: an exploratory study of key performance indicators. Planning Practice and Research. 2004; 19(1):101-110.

Basu, K. \& López-Calva, L. Functionings and capabilities. In Arrow K, Sen A, Suzumura K, editors. Handbook of social choice and welfare. Amsterdam: Elsevier; 2011. p. 153-187.

Beck T, Diaz del Castillo P, Fovet F, Mole H, Noga B. Applying Universal Design to Disability Service Provision: Outcome Analysis of a Universal Design (UD) Audit. Journal of Postsecondary Education and Disability. 2014; 27(2):209-222.

Berger-Schmitt R, \& Noll H-H.. Conceptual Framework and Structure of a European System of Social Indicators: EuReporting Working Paper No. 9. 2000 Mannheim, Germany: Centre for Survey Research and Methodology (ZUMA).

Borzaga C, Galera G, Franchini B, Chiomento S, Nogales R, Carini Ch. Social enterprises and their ecosystems in Europe. Comparative synthesis report. Luxembourg: Publications Office of the European Union; 2020. https://europa.eu/!Qq64ny. Accessed 7.11.2020.

Brown RI, Schalock RL \& Brown I. Quality of life: its application to persons with intellectual disability and their families: introduction and overview. Journal of Policy and Practice in Intellectual Disabilities. 2009; 6:2-6.

Buntinx WHE, Schalock RL. Models of disability, quality of life, and individualized supports: implications for professional practice in intellectual disability. Journal of Policy and Practice in Intellectual Disabilities. 2010; 7:283-94.

Cheshmehzangi A. The Reinvention of liveability in public places: interaction mapping Analysis of Central Nottingham's Improved Walkability. Journal of Human Behavior in the Social Environment. 2015;25(5):426-440.

Clayden A, McKoy K, Wild A. Improving residential liveability in the UK: home zones and alternative approaches. Journal of Urban Design. 2007; 11(1):55-71.

Comim F, Qizilbash M, Alkire S. The Capability Approach. Concepts, Measures and Applications. Cambridge: Cambridge University Press; 2008.

Crocker D., Ethics of Global Development: Agency, Capability and Deliberative Democracy. New York: Cambridge University Press; 2008.

Cummins RA. Moving from the quality of life concept to a theory. Journal of Intellectual Disability Research. 2005; 49:699706.

De Haan F, Ferguson B, Adamowicz R, Johnstone P, Brown R, Wong T. The needs of society: a new understanding of transitions. sustainability and liveability. Technological Forecasting and Social Change. 2013; 85:121-132. 
Diamantopoulos A, Siguaw JA. Formative vs. reflective indicators in measure development: Does the choice of indicators matter? British Journal of Management. 2006; 17(4):263-282.

Edwards JR, Bagozzi RP. On the nature and direction of relationships between constructs and measures. Psychological Methods. 2000; 5:155-174.

Emerson E, Einfeld SL. Challenging Behaviour (3rd ed). Cambridge: Cambridge University Press; 2011.

Eurostat. Final report of the expert group on quality of life indicators. 2016. https://ec.europa.eu/eurostat/web/productsstatistical-reports/-/KS-FT-17-004. Accessed 16.08.2020.

Eurostat. Sponsorship group on measuring progress. Well-being and sustainable development: final report adopted by the European Statistical System Committee. 2011. https://ec.europa.eu/eurostat/documents/7330775/7339383/SpG-Final-reportProgress-wellbeing-and-sustainable-deve/428899a4-9b8d-450c-a511-ae7ae35587cb. Accessed 10.07.2020.

Eurostat. Income and Living Conditions Data. 2020. https://ec.europa.eu/eurostat/web/income-and-living-conditions/data. Accessed 18.11.2020.

Felce D. Defining and applying the concept of quality of life. Journal of Intellectual Disability Research. 1997; 41:126-135.

Ferrans CE. Definitions and Conceptual Models of Quality of Life. In: Lipscomb J, Gotay CC, Snyder C, editors. Outcomes Assessment in Cancer. Measures, Methods, and Application. Cambridge: Cambridge University Press; 2005:14-30.

Field MJ, Jette AM. The future of disability in America. Institute of Medicine (US) Committee on Disability in America. Washington: National Academies Press (US); 2017.

Grills NJ, Hoq M, Wong Ch-PP, Allagh K, Singh L, Soji F, Murthy GVS. Disabled People's Organisations increase access to services and improve well-being: evidence from a cluster randomized trial in North India. BMC Public Health. 2020); 20:145. https://doi.org/10.1186/s12889-020-8192-0.

Guo Y, Hon Chan C, Chang Q, Liu T, Yip P. Neighborhood environment and cognitive function in older adults: A multilevel analysis in Hong Kong. Health \& Place. 2019; 58:102-146.

Hauser RM, Goldberger AS. The treatment of unobservable variables in path analysis. Sociological Methodology. 1971; 3:81117.

Hogg S, Medway D, Warnaby G. Towards a typology of marketing town center management schemes through the use of KPIs. Manchester Metropolitan University Working Paper. 2001; WP01/11.

Hornslien AG, Sandset EC, Bath PM, Wyller TB, Berge E.. Effects of candesartan in acute stroke on cognitive function and quality of life results from the Scandinavian candesartan acute stroke trial. Stroke. 2013; 44:2022-2023.

Howley P, Scott M, Redmond D. Sustainability versus liveability: an investigation of neighborhood satisfaction. Journal of Environmental Planning and Management. 2009; 52(6):847-867.

Jeromey B, Temple JB, Kelaher M, Williams R. Discrimination and avoidance due to disability in Australia: evidence from a National Cross Sectional Survey. BMC Public Health. 2018; 18:1347, https://doi.org/10.1186/s12889-018-6234-7.

Jöreskop KG, Goldberger AS. Estimation of a model with multiple indicators and multiple causes of a single latent variable. Journal of the American Statistical Association. 1975: 70(351):631-639.

Karr V. A life of quality: informing the UN convention on the rights of persons with disabilities. Journal of Disability Policy Studies. 2011; 22:66-82. 
Krishnakumar J. Going beyond functionings to capabilities: an econometric model to explain and estimate capabilities. Journal of Human Development and Capabilities. 2007; 8(1):39-63.

Kuklys W. Amartya Sen's Capability Approach: Theoretical Insights and Empirical Applications. Berlin: Springer; 2005.

Leby J, Hashim A. Their relative importance in the eyes if neighborhood residents. Journal of Construction in Developing Countries. 2010; 15(1):67-91.

Lorgelly P, Lorimer K, Fenwick E, Briggs A, Anand P. Operationalising the Capability Approach as an Outcome Measure in Public Health: The Development of the OCAP-18. Social Science \& Medicine. 2015; 142:68-81.

Maggino F, Zumbo BD. Measuring the quality of life and the construction of social indicators. In: Land KC, Michalos AC, Sirgy MJ, editors. Handbook of Social Indicators and Quality of Life Research. New York, NY: Springer; 2012. p.201-38.

Malbon E, Carey G, Meltzer A. Personalisation schemes in social care: are they growing social and health inequalities? BMC Public Health. 2019; 19:805. https://doi.org/10.1186/s12889-019-7168-4.

Milton S, Mold A, Tinker A, Herrick C. Growing old in new towns: A call for research on health and ageing in planned urban environments. Health \& Place. 2019; 58:102-166.

Neille J, Penn C. Beyond physical access: a qualitative analysis into the barriers to policy implementation and service provision experienced by persons with disabilities living in rural context. Rural and Remote Health. 2015; 15(3):1-15.

Newman P. Sustainability and cities: extending the metabolism model. Landscape Urban Planning. 1999; 33:219-226.

NRU. Promoting liveability: the experience of NDC-partnerships. London, England: ODPM. 2005.

O'Donovan MA, Doyle A Gallagher P. Barriers, activities and participation: incorporating ICF into service planning datasets. Disability and Rehabilitation. 2009; 31(25):2073-80. doi: 10.3109/09638280902918738.

Pacione M. Urban liveability: a review. Urban Geography. 1990; 11(1):1-30.

Panek T. Jakość życia. Od koncepcji do pomiaru [Quality of Life. From the concept to the measurement]. Warsaw: Warsaw School of Economics; 2016.

Parkes A, Kearns A, Atkinson R. What makes people dissatisfied with their neighborhoods? Urban Studies. 2002; 39(13):24132438.

Pawson R. Evidence-based policy. A realist perspective. London, UK: Sage Publications. 2006.

Pearl J. The casual foundations of structural equation modeling. In Hogle RH, editor. Handbook of Structural Equation Modeling. New York, NY: The Guilford Press; 2014. p. 68-91

Phillips D. Quality of life: concept, policy and practice. London, England: Routledge. 2006.

Rachele JN, Sugiyama T, Davies S, Loh V, Turrell G, Carver A, Cerin E. Neighbourhood built environment and physical function among mid-to-older aged adults: A systematic review. Health \& Place. 2019; 58:102-137.

Reinhardt JD, Miller J, Stucki G, Sykes C, Gray DB. Measuring impact of environmental factors on human functioning and disability: a review of various scientific approaches. Disability and Rehabilitation. 2011; 33(22-23):2151-2165.

doi.org/10.3109/09638288.2011.573053.

Robeyns I. Sen's Capability Approach and Gender Inequality: Selecting Relevant Capabilities. Feminist Economics. 2003; $9(2 / 3): 61-92$. 
Robeyns I. The Capability Approach: A Theoretical Survey. Journal of Human Development. 2005; 6(1):93-117.

Rószkiewcz M. Analiza klienta [Analysis of the client]. Cracow, Poland: Predictive Solutions.; 2011.

Schalock RL, Keith KD, Verdugo MA, Gomez LE.. Quality of life model development and use in the field of intellectual disability. In Kober R, editor. Quality of life: theory and implementation. New York, NY: Sage Publications. 2010. pp. 17-32.

Schlosberg D. Climate Justice and Capabilities: A Framework for Adaptation Policy. Ethics \& International Affairs. 2012; 26(4):445-461.

Sen A. Choice, Welfare and Measurement. Oxford: Basil Blackwell; 1982.

Sen A. Commodities and capabilities. Amsterdam, The Netherlands: North-Holland; 1985.

Sen A. Development as Freedom. New York, NY: Knopf; 1999.

Sen A. Equality of What? In McMurrin S, editor, Tanner Lectures on Human Values. Cambridge: Cambridge University Press; 1980.

Sen A. Inequality re-examined. Oxford, England: Clarendon Press; 1992.

Sen A. Inequality Reexamined. Oxford: Oxford University Press; 1992.

Sen A. Social Exclusion: Concept, Applications, and Scrutiny. Social Development Papers 1. Tokyo: Asian Development Bank; 2000.

Sen A. The Idea of Justice. London: Penguin Books; 2010.

Sen A. The Standard of Living, Cambridge University Press, Cambridge(1987),.

Sen A. Well-being, agency and freedom: the Dewey lectures 1984. The Journal of Philosophy. 1985; LXXXII(4):169-221.

Shafer CS, Koo Lee B, Turner S. A tale of three greenway trails: user perceptions related to quality of life. Landscape Urban Planning. 2000; 49:163-178.

Sirgy MJ. The Psychology of Quality of Life. Hedonic Well-Being, Life Satisfaction, and Eudaimonia. Springer Science \& Business Media; 2012.

Slabbert I. Applying the Capability Approach in Social Work Education. Social Work Education. 2018; 37(7):867-881.

Smith T, Nelischer M, Perkins N. Quality of an urban community: a framework for understanding the relationship between quality and physical form. Landscape Urban Planning. 1997; 39(2-3):229-241.

Stiglitz J, Fitoussi JJ, Durand M. Beyond GDP: Measuring What Counts for Economic and Social Performance. Paris: OECD Publishing; 2018. https://doi.org/10.1787/9789264307292-en.

Stiglitz JE, Sen A, Fitoussi JP. Report by the Commission on the Measurement of Economic Performance and Social Progress. 2009. www.stiglitz-sen-fitoussi.fr. Accessed 15.09.2020.

Taft C, Magnusson ES, Ekstedt G, Malmgren K. Health-related quality of life, mood, and patient satisfaction after epilepsy surgery in Sweden - a prospective controlled observational study. Epilepsia. 2014; 55(6):878-882.

Toro-Hernandez ML, Villa-Torres L, ,Mondragón-Barrera MA, Camelo-Castillo W. Factors that influence the use of community assets by people with physical disabilities: results of participatory mapping in Envigado, Colombia. BMC Public Health. (2020; 20:181, https://doi.org/10.1186/s12889-020-8285-9. 
United Nations Development Programme. Krajowy raport o rozwoju społecznym: Polska 2012. Rozwój regionalny i lokalny [National report on social development: Poland 2012. Regional and local development]. Warsaw, Poland: UNDP Office in Poland. 2012.

United Nations. The Convention on Rights of Persons with Disabilities. 2006. https://www.un.org/development/desa/disabilities/convention-on-the-rights-of-persons-with-disabilities.html. Accessed 7.03.2020.

van Kamp I, Leidemeijer K, Marsman G, de Hollander A. Urban environmental quality and human well-being: towards a conceptual framework and demarcation of concepts: a literature study. Landsc. Urban Plan. 2003; 65:5-18.

Verdugo MA, Gómez LE, Schalock RL, Arias B. The integral quality of life scale: development, validation and use. In Kober R, editor. Enhancing the quality of life of people with intellectual disabilities: from theory to practice. Dordrecht, Germany: Springer; 2010. p. 47-60.

Visagie S, Eide AH, Dyrstad K, Mannan H, Swartz L, Schneider M, MacLachlan M. Factors related to environmental barriers experienced by persons with and without disabilities in diverse African settings. PloS One. 2017; 12(10), e0186342. doi:10.1371/journal.pone.0186342.

Węziak-Białowolska D. Quality of life in cities - empirical evidence in comparative European perspective. Cities. 2016; 58:87-96. World Health Organization.. Measuring quality of life. Geneva, The Switzerland: WHO; 1997.

Yafei L, Dijst M, Faber J, Geertman S, Cui C. Healthy urban living: residential environment and health of older adults in Shanghai. Health \& Place. 2017; 47:80-89.

Zhang W. Research on how to improve the liveability of city community. Applied Mechanics and Materials. 2012; 174177:3503-3506.

\section{Figures}




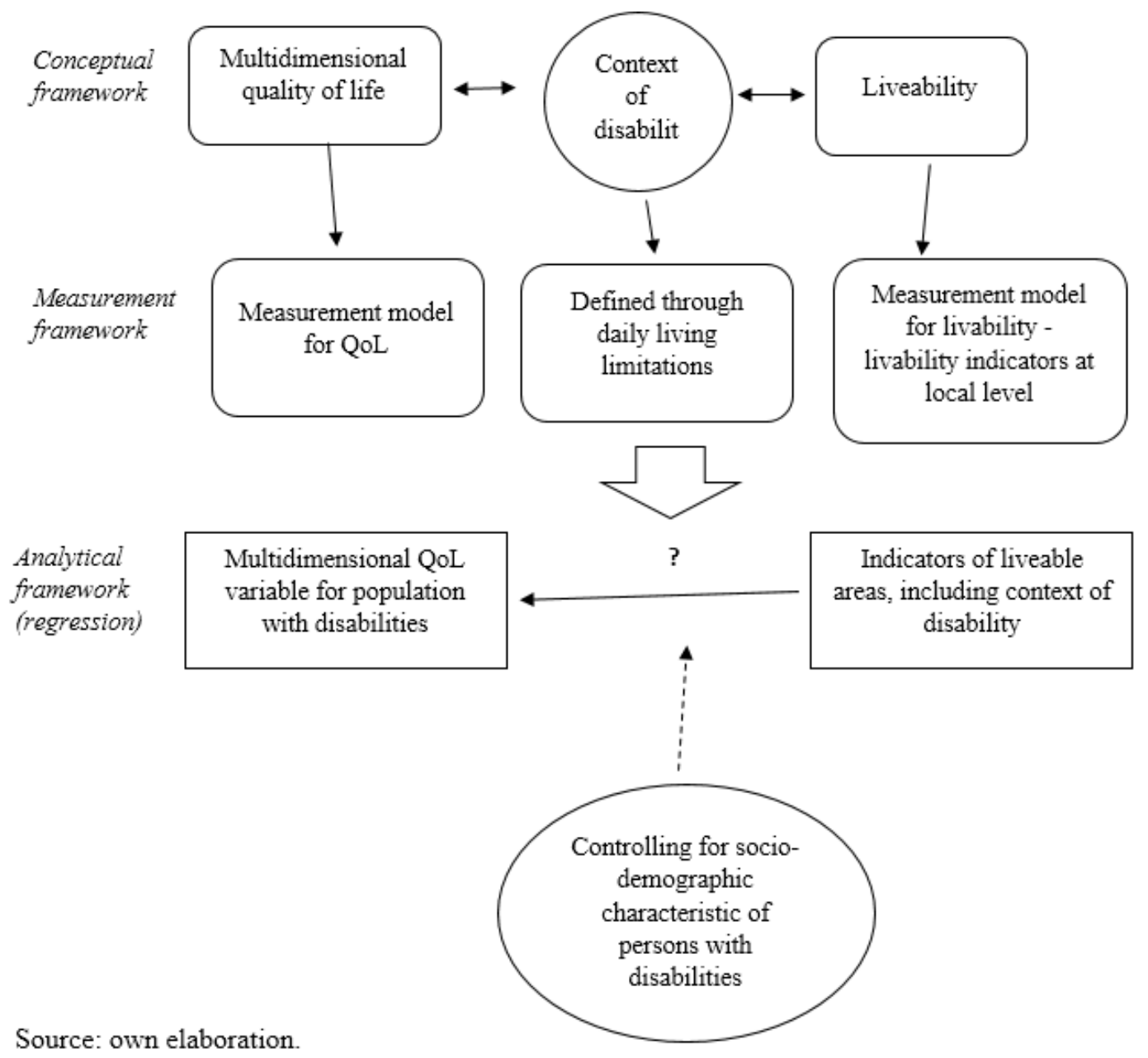

\section{Figure 1}

\section{Research design}

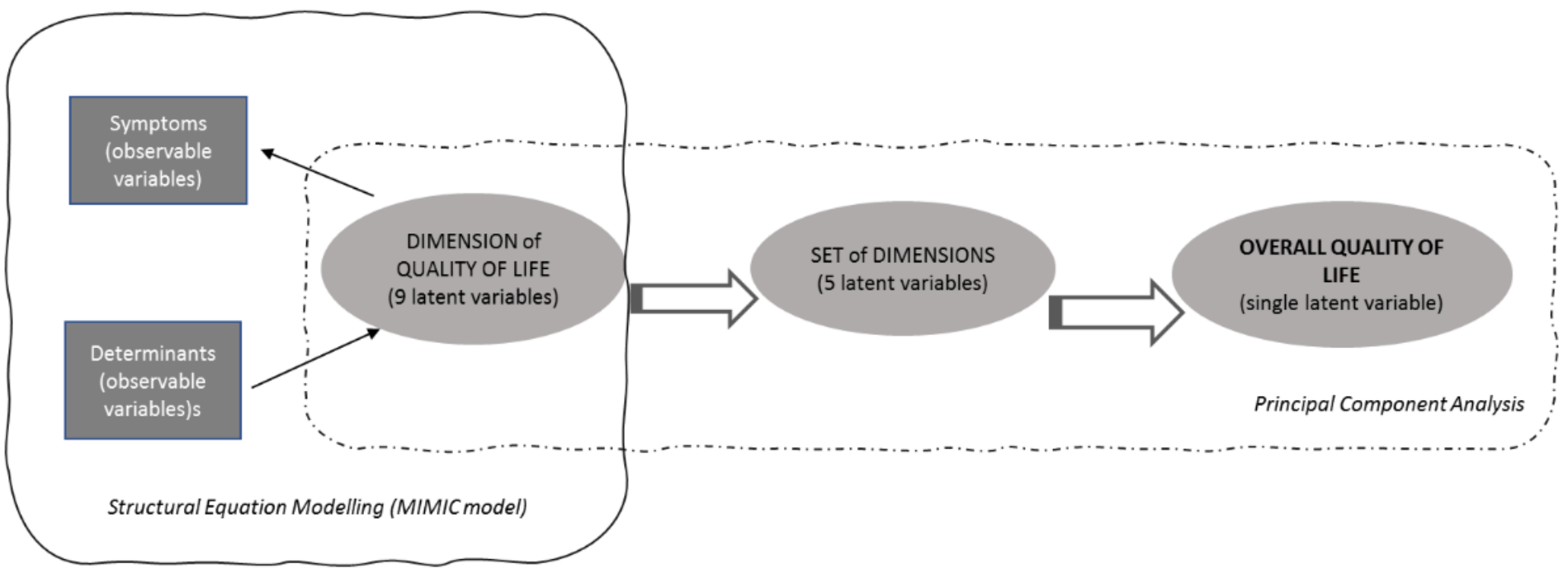

\section{Source: own elaboration.}

\section{Figure 2}

The measurement model of the QoL 


\section{Supplementary Files}

This is a list of supplementary files associated with this preprint. Click to download.

- Annex1ver2.docx

- Annex2ver2.docx 